\title{
Mental Health of Small Children for Normal Gestational Age: A Cohort Study from Southeastern Brazil
}

\author{
Saúde Mental em Crianças Nascidas Pequenas para Idade Gestacional: \\ Estudo de Coorte do Sudeste Brasileiro
}

\author{
Adriana Martins Saur*, ${ }^{a, b}$ \& Sonia Regina Loureiro ${ }^{b}$ \\ ${ }^{a}$ Centro Universitário Barão de Maná, Ribeirão Preto, SP, Brasil \\ $\&{ }^{b}$ Universidade de São Paulo, Ribeirão Preto, SP, Brasil
}

\begin{abstract}
The aim of this study is to investigate mental health problems in children born small for gestational age (SGA) and those born appropriate for gestational age (AGA) and to assess the association of these problems with child and family characteristics. Six hundred and seventy-seven children, belonging to a birth cohort from 1994 in Ribeirão Preto/SP (southeastern Brazil), were evaluated (140 SGA and 537 AGA). They were later reevaluated at school age (2004/2005) by means of the Strengths and Difficulties Questionnaire for mental health assessment (parent report). Results showed that children born SGA presented greater frequency of behavioral problems and emotional symptoms compared to children born AGA. Variables associated with mental health problems in the univariate model were: male sex, children born SGA, low educational level of parents, socioeconomic disadvantage, and belonging to families with many members. However, in multivariate analysis, two factors being born SGA and father's low educational level - lost their statistical significance, and the other sociodemographic variables remained significant (male sex, low-level of maternal education, low socioeconomic level, families with many members). It has been concluded that being born SGA was not independently associated with mental health problems, but sociodemographic factors proved to be the predictors of this type of problem in the cohort studied.

Keywords: Mental health, child development, gestational age, cohort studies.
\end{abstract}

\section{Resumo}

Este estudo objetivou investigar problemas de saúde mental em crianças nascidas pequenas para a idade gestacional (PIG) e adequadas para a idade gestacional (AIG), além de verificar também as possíveis associações destes problemas com variáveis biológicas e sociodemográficas. Foram avaliadas 677 crianças (140 PIG e 537 AIG), pertencentes a uma coorte de nascimento do ano de 1994, em Ribeirão Preto/SP (sudeste do Brasil), reavaliadas na idade escolar (2004/2005), por meio do Questionário de Dificuldades e Capacidades (versão dos pais). Os resultados mostraram que as crianças nascidas PIG apresentaram maior frequência de problemas comportamentais e sintomas emocionais, em comparação às crianças nascidas AIG. As variáveis associadas a problemas de saúde mental, no modelo univariado, foram o sexo masculino, crianças nascidas PIG, baixa escolaridade materna e paterna, desvantagem socioeconômica e famílias mais numerosas. Entretanto, na análise multivariada, a condição de nascimento PIG e a escolaridade paterna perderam sua significância estatística, permanecendo somente associadas às demais variáveis sociodemográficas (sexo masculino, baixa escolaridade materna, nível socioeconômico mais baixo e famílias mais numerosas). Conclui-se que a condição de nascimento PIG não foi independentemente associada a problemas de saúde mental, tendo os fatores sociodemográficos se mostrado como melhores preditores deste tipo de problema na coorte estudada.

Palavras-chave: Saúde mental, desenvolvimento infantil, idade gestacional, estudos de coortes.

\footnotetext{
${ }^{*}$ Mailing address: Rua Jaqueira 81, Jardim Recreio, Ribeirão Preto, SP, Brasil, 14040-270. E-mail: adrianasaur@ yahoo.com.br and srlourei@fmrp.usp.br

Acknowledgements: This study was supported by FAPESP (São Paulo Research Foundation) and CNPq (National Council of Technological and Scientific Development)
}

Behavioral performance of children has been considered an important indicator of mental health and future development. Most of the literature suggests that biological and social conditions are associated with child mental health problems (Masten \& Gerwitz, 2006; Sameroff \& Fiese, 2005), thus it is essential to study the 
impact of these risk conditions for a better understanding of the issues. Social factors frequently associated with behavioral problems include the socioeconomic conditions of families, such as maternal/paternal education level and socioeconomic status (Anselmi et al., 2010; Hollo et al., 2002; Pallotto \& Kilbride, 2006; Rodriguez, Silva, Bettiol, Barbieri, \& Rona, 2011). Among the main biological conditions are birth weight, gestational age, intrauterine growth restriction, and anthropometric indices (Sameroff $\&$ Fiese, 2005). Much has been studied in relation to developmental outcomes of children with low birth weight and those who are very preterm (Bhutta, Cleves, Casey, Cradock, \& Anand, 2002; Emond, Lira, Lima, GranthamMcGregor, \& Ashworth, 2006; Hayes \& Sharif, 2009), but studies on the impact of being small for gestational age (SGA) are sparser, especially in Brazil.

The survival of SGA children has increased considerably in the last few decades, especially due to advances in neonatal care and medical technology (Hollo et al., 2002; Pallotto \& Kilbride, 2006). Nevertheless, developmental outcomes for this group are less clear and follow up studies still show conflicting results. Furthermore, methodological difficulties related to the definition of this criterion have contributed to the controversy surrounding the relationship of SGA children to adverse outcomes (Gardosi, 2006; Goldenberg, Hoffman, \& Cliver, 1998; Lundgren \& Tuvemo, 2008; Pallotto \& Kilbride, 2006).

Although a significant proportion of SGA children are functioning within the normal range (Casey, Whiteside-Mansell, Barret, Bradley, \& Gargus, 2006; Sommerfelt et al., 2001; Wiles et al., 2006; Winchester et al., 2009), the condition is related to a wide range of negative outcomes at school age, such as lower cognitive function, poor academic achievement, and more behavioral and mental health problems than children who are born appropriate for gestational age (Gallo et al., 2011; Guellec et al., 2011; Hollo et al., 2002; Indredavik, Vik, Heyerdahl, Kulseng, \& Brubakk, 2005; Lundgren \& Tuvemo, 2008; Pallotto \& Kilbride, 2006; Pryor, Silva, \& Brooke, 1995; Zubrick et al., 2000).

Child development in developing countries like Brazil can easily be hindered by conditions associated with poverty and adverse social factors, preventing these children from reaching their full developmental potential (Walker et al., 2007). In this context, studying the association between mental health outcomes, perinatal conditions and social environment become extremely important in the identification of biological and sociocultural risk factors. Many authors agree that it is necessary to consider culture and context in determining the way in which the psychopathology of children may be manifested. There is also evidence that child disorders may vary between developed and developing countries, making it necessary to distinguish each study by country (Canino \& Alegria, 2008; Hackett \& Hackett, 1999). In fact, Kieling et al. (2011) and Rohde (2011) considered that a major gap in the epidemiology of child mental disorders is due to the lack of studies regarding mental health problems in low to middle income countries.

In Brazil there are few cohort studies addressing the association between mental health problems and small for gestational age children, rendering this study a relevant contribution to the mental health outcomes of children. Prospective birth cohort studies can elucidate the association of genes and environment, as well as their interactions with neurobehavioral development (Thompson et al., 2010). Accordingly, we provide information to identify and prevent more effectively potential psychopathologies in developing countries, helping to outline intervention strategies for the most vulnerable children and families.

The aim of this study is to provide information on mental health problems of small for gestational age children at age 10 among a Brazilian cohort of both children born SGA and those born appropriate for gestational age (AGA); and to assess the association of these problems with child and family characteristics.

\section{Method}

\section{Ethics}

The Research Ethics Committee of the University of São Paulo approved this study, and no incentives were provided to the schools or student participants.

\section{Study Design and Data Collection}

This study was part of a large prospective and longitudinal cohort study, conducted in the city of Ribeirão Preto, State of São Paulo, Southeastern Brazil. The basic study design and details of the study population have been previously described (Cardoso et al., 2007).

In short, the large study was conducted in two phases. The first phase took place between April 1994 and August 1994, during which time data were collected regarding a sample of 3,663 live-born infants delivered at 10 maternity hospitals in the city of Ribeirão Preto, representing 99\% of all live births. The following information was obtained through a standard questionnaire applied during interviews with the mothers immediately after birth and oral consent: anthropometric data (weight and length), gestational age, and data related to social factors (marital status, maternal and paternal education and number of household members). Socioeconomic status was collected at school age. Children whose mothers did not live in the studied area (733/20\%) and twin births (84/2.3\%) were excluded from the study; the sample size of this cohort was reduced to 2,846 individuals.

A follow-up study, corresponding to the second phase of the larger study was conducted in 2004/2005, with school-aged children (10 years). To locate the sample of schoolchildren enrolled in the 125 elementary schools existing in Ribeirão Preto, a general student registry man- 
aged by the State Department of Education (encompassing all types of schools - municipal, state, private and special classes), was consulted. The full names of the students and their parents, as well as school and grade, were obtained. Some children not identified in schools were located through an active search starting from addresses recorded on the birth questionnaires. Once an individual belonging to the cohort was identified, the family was contacted by phone. The child's legal guardian was then invited to attend a meeting at school. After the reasons for the evaluation were explained, written informed consent was requested from the legal guardians and children, specifying the various stages of the study (clinical and psychological evaluation). Of the 2,846 children participating in the first phase, 1,138 (40\%) were found. Of the 1,138 children located, data on 677 (59.5\%) children were available. The main reason related to this loss of follow up data is that the respective telephone numbers provided upon birth of the children (1994) were no longer the same and/or the children's names were not on the school registration lists furnished by the State Department of Education. Great physical/geographical mobility in search of a better life and living conditions in the 1990s created difficulty in accessing these families, especially one decade later. Another crucial issue has to do with the telephone contacts provided upon birth: in 1994 (the year in which the cohort began) cellular phones still didn't exist, and few residences (especially those of low income) had fixed telephones. As such, the telephone numbers given were essentially commercial and meant for "leaving messages", which also made re-contact difficult ten years later.

Ten people divided into two teams, each containing four students of psychology and a senior psychologist in charge, carried out data collection.

Comparison of the characteristics of the participants at birth and school age is presented elsewhere (Silva et al., 2011). In brief, a lower percentage of children who participated in the follow-up study were born to cohabiting mothers, to mothers aged $<20$ years, and with $\leq 4$ years of schooling, in comparison to eligible children who did not participate; but there was no difference regarding maternal parity and offspring sex.

\section{Study Population}

There were 677 children (345/51\% males and 332/49\% females) evaluated, aged 10/11 years (mean 10.7 years) at the time of evaluation, distributed among two groups according to birth weight percentile corrected for gestational age. The SGA group (140/20.7\%) was defined as children whose birth weights were below the 10th percentile for gestational age, and the AGA group (537/79.3\%) including children whose birth weights were greater than or equal to the 10th percentile (Alexander, Himes, Kaufman, Mor, \& Kogan, 1996). Gestational age was based on last menstrual period.

\section{Instruments and Measures}

Mental health assessment was conducted using the Portuguese (Brazilian) version of the Strengths and Difficulties Questionnaire (SDQ), designed to screen behavioral problems of children and adolescents between 4 and 16 years of age (Goodman, 1997). It contains four scales that assess psychiatric symptoms (emotional problems, conduct problems, hyperactivity and peer problems) and a scale that reflects prosocial behavior. Scores are assigned to each of these scales $(0,1$ or 2 as false, true, or somewhat true), and scores for the four symptom scales are summed up to provide a "total difficulties score" ranging from 0 to 40 , with higher scores indicating more behavioral problems. The cut-off point (punctuation on total difficulties score $>$ 16) refers to abnormal range and scores below this value were classified as normal range. In the present study, a parent report version was used.

Assessment of child and family characteristics: data on birth weight (grams), gestational age (weeks) and gender, as well as data on maternal and paternal education (low: $\leq$ 8 and high: $>8$ years of study), marital status (married or unmarried), and number of household members ( $\leq 4$ and $>$ 4 members) were collected at the time of the child's birth, obtained from an interview with the mother. The assessment of socioeconomic status was collected upon reaching school age, also through an interview with the mother. For this purpose, we used a standard Brazilian Questionnaire (Associação Brasileira de Empresas de Pesquisa, 2008) that evaluates the purchasing power of consumer groups (levels A1, A2, B1, B2 corresponding to the most favored economic classes, and levels C1, C2, D and E corresponding to the disadvantaged economic classes).

\section{Statistical Analysis}

Descriptive statistics were computed for the sociodemographic characteristics of children and their families for SGA and AGA groups. Chi-square test was used to compare child variables (birth weight, gestational age and gender), social characteristics (marital status, maternal and paternal education, socioeconomic status and number of household members), and frequency distribution for the abnormal range on all SDQ subscales across the groups (SGA/AGA). To examine the association between mental health problems (considered abnormal range on SDQ total difficulties score) and child and family characteristics, we used univariable and multivariable binary logistic regression analysis (CI 95\%). As a first step, crude odds ratio was calculated, then to control for possible confounders, we calculated adjusted odds ratio. In the multivariable regression analysis, adjustment was performed for all independent variables (gender, birth weight according to gestational age, condition regarding gestational age, marital status, maternal and paternal education, socioeconomic status and number of household members). All of them were treated as categorical (binary variables). In regression analyses, the reference (or comparison) group 
Saur, A. M. \& Loureiro, S. R. (2015). Mental Health of Small Children for Normal Gestational Age: A Cohort Study from Southeastern Brazil.

was chosen (when appropriate) as the hypothesized lowest risk group.

All analyses were considered to be statistically significant when the $p$-value was $\leq .05$. Statistical analysis was carried out using SPSS for Windows (version 17.0).

Table 1

Child and Family Characteristics for SGA and AGA Children*

\begin{tabular}{|c|c|c|c|}
\hline & $\begin{array}{c}\text { SGA } \\
n=140\end{array}$ & $\begin{array}{c}\text { AGA } \\
n=537\end{array}$ & $p$ value \\
\hline \multicolumn{4}{|l|}{ Child characteristics } \\
\hline Birth weight $(\mathrm{g})^{\#}$ & $2267(464)$ & $3214(587)$ & .01 \\
\hline Gestational Age (weeks) & $37.5(2.5)$ & $38(2.5)$ & .08 \\
\hline \multicolumn{4}{|l|}{ Condition $^{+}$} \\
\hline Preterm & $41(29.0)$ & $113(21.0)$ & \multirow{2}{*}{.04} \\
\hline Term & $99(71.0)$ & $424(79.0)$ & \\
\hline \multicolumn{4}{|l|}{ Gender $^{+}$} \\
\hline Male & $51(36.4)$ & $294(54.7)$ & \multirow{2}{*}{.01} \\
\hline Female & $89(63.6)$ & $243(45.3)$ & \\
\hline \multicolumn{4}{|l|}{ Family characteristics ${ }^{+}$} \\
\hline \multicolumn{4}{|l|}{ Marital Status } \\
\hline Married & $110(80.9)$ & $439(86.4)$ & \multirow{2}{*}{.11} \\
\hline Unmarried & $26(19.1)$ & $69(13.6)$ & \\
\hline \multicolumn{4}{|l|}{ Maternal education } \\
\hline Low ( $\leq 8$ years of study) & $93(70.5)$ & $293(59.9)$ & \multirow{2}{*}{.03} \\
\hline High ( $>8$ years of study) & $39(29.5)$ & $196(36.5)$ & \\
\hline \multicolumn{4}{|l|}{ Paternal education } \\
\hline Low ( $\leq 8$ years of study) & $78(70.3)$ & $259(57.7)$ & \multirow{2}{*}{.01} \\
\hline High ( $>8$ years of study) & $33(29.7)$ & $190(42.3)$ & \\
\hline \multicolumn{4}{|l|}{ Socioeconomic status } \\
\hline Most favored economic classes & $41(29.5)$ & $220(41.4)$ & \multirow{2}{*}{.01} \\
\hline Disadvantaged economic classes & $98(70.5)$ & $311(58.6)$ & \\
\hline \multicolumn{4}{|l|}{ Number of household members } \\
\hline$\leq 4$ members & $79(59.4)$ & $352(68.8)$ & \multirow{2}{*}{.04} \\
\hline$>4$ members & $54(40.6)$ & $160(31.3)$ & \\
\hline
\end{tabular}

Note. SGA, small for gestational age; AGA, appropriate for gestational age. *The number of children on whom data were available varied by background characteristic. ${ }^{\#}$ Values are mean $(S D) .{ }^{+}$Values are number $(\%)$.

When compared to the AGA group, SGA children presented significantly lower average birth weight (as expected), higher proportion of children born preterm, and more women. Regarding family characteristics, the SGA group showed significantly lower maternal and paternal education, a higher proportion of disadvantaged economic classes, and more numerous families. No differences were

\section{Results}

Results for child and family characteristics are presented in Table 1. 
Psicologia: Reflexão e Crítica, 28(1), 204-212.

Table 2

Number and (percentage) of Children Rated Abnormal by Parents in SDQ Subscales for SGA and AGA Children

\begin{tabular}{lccc}
\hline \multicolumn{1}{c}{ SDQ subscales } & SGA $(n=139)^{\#}$ & AGA $(n=534)^{+}$ & $p$ value* \\
\hline Total difficulties score & $65(46.8)$ & $192(36.0)$ & .019 \\
Emotional symptoms & $96(69.1)$ & $267(50.0)$ & .001 \\
Hyperactivity & $37(26.6)$ & $132(24.7)$ & .645 \\
Conduct problems & $49(35.3)$ & $175(32.8)$ & .580 \\
Peer problems & $44(31.7)$ & $137(25.7)$ & .155 \\
Prosocial behavior & $4(2.9)$ & $21(3.9)$ & .558 \\
\hline
\end{tabular}

Note. SGA, small for gestational age; AGA, appropriate for gestational age. \# Data on SDQ were missing for one child. ${ }^{+}$Data on SDQ were missing for three children. ${ }^{*} p$ value was obtained from chi-square test.

Table 3

Univariable and Multivariable Binary Logistic Regression for Identifying Associations between Child/Family Characteristics and Mental Health Problems (abnormal range) on SDQ Total Difficulties Score

\begin{tabular}{lccc}
\hline Variables & Crude OR & & Adjusted OR * \\
{$[95 \% \mathrm{CI}]$} & $p$ value & $p$ value
\end{tabular}

Gender $(n=677)$

Female

Male

Reference

1.35 [.99-1.85]

Reference

$1.56[1.07-2.28]$

Reference

$1.08[.75-1.56]$

Reference

1.28 [.82-1.99]

2.67 [1.86-3.82]

Reference

High ( $>8$ years of study)

Paternal education $(n=560)$

Low ( $\leq 8$ years of study)

High ( $>8$ years of study)

Socioeconomic status $(n=670)$

Most favored economic classes

Disadvantaged economic classes

$\mathrm{N}^{\circ}$ of household members $(n=645)$

$\leq 4$ members

$>4$ members
$2.76[1.89-4.03]$

Reference

Reference

$2.56[1.82-3.60]$

Reference

$1.91[1.36-2.67]$
.02

.05

Reference

1.58 [1.07-2.32]

Reference

$1.30[.82-2.06]$

Reference

1.03 [.60-1.44]

Reference

1.10 [.61-1.98]

.01

1.71 [1.06-2.74]

Reference

.01

1.51 [.92-2.48]

.11

Reference

Reference

1.60 [1.00-2.56]

.05

Reference

1.57 [1.05-2.37]

Note. * Adjustments made for all variables in the table. 
The SGA group presented significantly more frequency of children with behavioral problems (according to the total difficulties score) and emotional symptoms when compared to children from the AGA group. There was no difference in frequency distribution between children from the SGA and AGA groups regarding hyperactivity, conduct problems, peer problems, and prosocial behavior scales.

The associations between child/family characteristics and mental health problems (according to the abnormal range on SDQ total difficulties score) are presented in Table 3.

Results shows that in a non-adjusted model (crude odds ratio), gender (male sex), small for gestational age children, maternal and paternal education (lower years of study), socioeconomic status (disadvantaged economic classes), and the number of family members living in the household (more than 4) were associated with mental health problems. After adjustment for confounding factors, the only variables that remained associated with mental health problems were gender (male sex), low maternal education, disadvantaged economic classes (borderline significance), and more than four family members living in the household.

\section{Discussion}

A first issue to be addressed is that being born small for gestational age was not independently associated with mental health problems. It seems that when we control for possible confounders, fetal growth loses its statistical significance in favor of other background characteristics, such as sociodemographic variables (lower parental education, poorer socioeconomic status and more numerous families). Gallo et al. (2011) found similar results in evaluating the association between SGA children (birth weight $<10^{\text {th }}$ percentile according Kramer criteria) and mental health problems at 11 years of age in the Brazilian cohort, also using the SDQ. The SGA condition was only associated with mental health problems in a non-adjusted model; and after adjusting for potential confounders (including child and family sociodemographic conditions) the only remaining associated variables were size measurements at birth (weight and body mass index for age $z$-scores).

Rodriguez et al. (2011) assessed the influence of perinatal and social factors on mental health problems in children aged 7-9 years in a Brazilian cohort study, also using the SDQ. Although they did not study SGA children specifically, they concluded that socioeconomic and demographic conditions were better predictors of mental health problems in children than perinatal conditions (such as birth weight or preterm birth). Emond et al. (2006) investigated development and behavior of low birth weight term infants at 8 years old in northeastern Brazil. Their results showed that birth weight was not associated with behavioral problems in all SDQ scales (except peer problems), concluding that social background (maternal education, home stimulation and type of school attended) were the real determinants for developmental outcomes. In another Brazilian cohort study, early determinants of attention and hyperactivity problems at 11 years were investigated (Anselmi et al., 2010). No association was found between intrauterine growth restriction (Kramer criteria) and hyperactivity problems (assessed by SDQ), although they observed association with low family income and male sex. In a revisionary study on outcomes for children who had intrauterine growth restriction (IUGR), including SGA children, Pallotto and Kilbride (2006) also found that low socioeconomic status is correlated with the occurrence of IUGR and is significantly related to long-term disabilities. These results lead us to further highlight the importance of the social environment in which the child develops, where socioeconomic status has an important impact on ultimate outcomes, perhaps more than biological conditions at birth, as found in the present study.

However, there are also divergent results. When studying risk factors for adverse outcomes in developing countries, Walker et al. (2007) identified four key risk factors that urgently need intervention: stunting, inadequate cognitive stimulation, iodine and iron deficiency. The evidence was also sufficient to warrant interventions for malaria, intrauterine growth restriction, maternal depression, exposure to violence and exposure to heavy metals. None of the social or economic characteristics that were studied here appears as a risk factor in Walker et al. (2007), although intrauterine growth restriction (IGR) has been shown to be an adverse outcome. However, we did not study IGR (defined by authors as birth weight $<2500 \mathrm{~g}$ and gestational age $\geq 37$ weeks), and all the children assessed by Walker et al. (2007) in developing countries were younger - ranging from 1 to 3 years old - than those assessed in the present study.

Our results also disagree with two Brazilian studies. Linhares, Chimello, Bordin, Carvalho and Martinez (2005) found no association between maternal education and mother's occupation concerning behavioral development (assessed by Rutter Child Behavior Scale) of children born pre-term and at term; and Ferrioli, Marturano and Puntel (2007) found no association between socioeconomic status and behavioral/emotional problems in school children (assessed by SDQ). However, we assign these differences to methodological issues, like type and sensitivity of the measures used, sample size, and composition of the sample (neither were cohort studies).

Despite the fact that SGA was not a predictor of behavioral problems, our study showed that a higher proportion of SGA children presented more mental health problems (assessed by the SDQ total difficulties score) and emotional symptoms than AGA children at 10 years old; whereas no difference was found for frequency distribution on hyperactivity, conduct problems, peer problems, and prosocial behavior scales.

The higher proportion of SGA children scoring in the abnormal range of the SDQ total difficulties score can be affected by an elevated rate of emotional symptoms, 
since almost $70 \%$ of the SGA group presented emotional problems, representing a percentage much higher than the other SDQ subscales. And, as no significant differences were found for hyperactivity, conduct problems and peer problems, it is highly possible that the mental health problems found in SGA children can be more associated with emotional problems.

These results are consistent with many studies that found that SGA children indeed have an increased risk for behavioral and emotional problems. In a review study, Lundgren and Tuvemo (2008) found that there is cumulative evidence suggesting an association between being born SGA and increased risk of lower intelligence, poor academic performance, low social competence, and behavioral problems compared to individuals born appropriate for gestational age. In another review on perinatal outcomes and later implications of intrauterine growth restriction, Pallotto and Kilbride (2006) reported that behavioral and emotional problems are more frequently found among children who were SGA. Indredavik et al. (2005) explored psychiatric symptoms in low birth weight and SGA adolescents (birth weight $<10$ th percentile) at 14 years of age, and concluded that SGA adolescents may have discrete emotional, behavioral and attention deficit symptoms, assessed by The Achenbach System of Empirically Based Assessment (ASEBA) and the Strengths and Difficulties Questionnaire. Hollo et al. (2002) reported that children born SGA (defined as birth weight for gestational age below the 2.5th percentile) are more likely to be socially withdrawn, restless in the classroom, overtly timid and have more learning problems than AGA children, at the age of 10 (assessed by Conners Parent and Teacher Rating Scales). Pryor et al. (1995) also found more behavioral problems in the total difficulties score among SGA children at 13 years (weight $<10$ th percentile and $\geq 37$ weeks), while no difference was found on the hyperactivity scale (assessed by Revised Problem Behaviour Checklist). More behavioral problems in children who were smaller at birth - such as attention, aggression, socialization and thought problems - were also found in Zubrick et al. (2000), although the authors used the percentage of expected birth weight as criteria for fetal growth, along with the Child Behavior Checklist (CBCL) and the Teacher Report Form for behavioral assessment. O'Keeffe, O'Callaghan, Williams, Najman, and Bor (2003) investigated attentional problems in adolescents born SGA $(<10$ th percentile) assessed by Youth Self Report and concluded that SGA status seems to have modest independent effects on attention in adolescence.

On the other hand, there are other studies that found no differences between behavioral outcomes among SGA children and their controls. In studying neurological outcomes at school age in very preterm infants born SGA $(<10$ th percentile) or mild-SGA (10th-19th percentile), Guellec et al. (2011) found no difference for behavioral problems (assessed by SDQ total difficulties score) between SGA or mild-SGA and the AGA group at the age of 5 years, although they concluded that both
SGA and mild-SGA were associated with mortality and with cognitive and school difficulties. Winchester et al. (2009) investigated behavioral outcomes at age 12 in SGA children (birthweight $<10$ th percentile) using the Teacher Report Form. The SGA group was found to be equivalent to full-term peers regarding social skills and behavioral problems. Wiles et al. (2006) concluded that there was a weak association between intrauterine fetal growth restriction (index by birth weight and length) and childhood behavioral problems at the age of 7 years (assessed by SDQ). Casey et al. (2006) found no difference in behavioral status for SGA children (weight $<10$ th percentile on the Lubchencho curves) assessed by CBCL at the age of 8; and Sommerfelt et al. (2001) found that being born moderately SGA (birthweight $<15$ th percentile for gestational age) is not a significant risk factor for preschool behavior problems.

It is important to emphasize the difficulty in comparing our results with the literature, due to the different methodologies used in each study. As stated by Goldenberg et al. (1998), one of the major reasons for the controversy surrounding the relationship between SGA and adverse developmental outcomes is that infants who are considered SGA in one study are not necessarily deemed SGA in other studies. Most of the authors define SGA as including infants born below the tenth percentile of birth weight for gestational age, but the problem is that the standards used to define this tenth percentile cut-off are very different from one study to the next. Gardosi (2006) also comments that maternal height, weight, parity, and ethnic origin have all been found significantly associated with normal variation in birth weight, so that these variables need to be adjusted to calculate the true growth potential. This can be represented as individually customized fetal growth curves and birth weight percentiles.

Another important issue is that there are gender differences regarding birth weight, which directly affects the inclusion criteria for SGA children. Since girls generally weigh less than boys, studies not using gender-specific standards will include a larger proportion of the female population and a smaller proportion of the male population, as found in this study (64\% SGA females). In addition, there should also be concern about the gestational ages of the infants studied, since preterm SGA infants may have different outcomes than term SGA infants, becoming an important factor in defining the gestational age ranges in populations under study (Goldenberg et al., 1998; Indredavik et al., 2005; Lundgren \& Tuvemo, 2008). In this study, $71 \%$ of SGA children were born at term, almost the same proportion as the AGA group (79\%). This raises a question: if most of the SGA and AGA children were born at term, what possible factors could explain the different results among these groups? First, as mentioned, there are many more females in the SGA group, which can help us understand the highest frequency distribution on the emotional symptoms scale, since the literature indicates that girls tend to have more internalizing problems than boys (Cury \& Golfeto, 2003; Zahn-Waxler, Klimes-Dougan, 
\& Slattery, 2000). On the other hand, the literature also describes boys as scoring significantly higher on the total difficulties score (Cury \& Golfeto, 2003), which leads us to believe that there are other aspects to be considered besides gender.

Regarding family characteristics, socioeconomic status and parental basic education were significantly better in AGA than in SGA children. In Brazil, families with more educational and financial resources tend to have better access to doctors and preventive health programs, which may have acted as a protective factor for the AGA group, producing more positive behavioral outcomes. This conclusion becomes even more evident when we observe the results of the associations between child/family characteristics and mental health problems. In this study, the variables associated with behavioral problems at the age of 10 were: being male, belonging to families with low maternal educational level, low socioeconomic status, and more than four household members.

Another aspect that needs to be addressed is related to the loss of follow up, since there was a significant depreciation from the sample used in the initial cohort (1994), as the number of subjects eligible for follow up (2004) diminished. We are aware that a decrease in the original sample is an unavoidable problem in any study of this type, but in developing countries like Brazil the loss can be markedly higher, especially when the cohort mostly comprises individuals from disadvantaged economic classes with lower level of education, as is presently the case. Cultural issues and unfavorable social factors often compromise the understanding of how valuable this kind of research is, hindering the collaboration of a wealth of participants. In addition, the economic instability of the country leads people to move frequently, making it difficult to find them again. Furthermore, with the popularization of low-cost mobile phones in Brazil in the 2000s, a significant number of landlines, easily located through telephone directories, were disabled. Accordingly, it was not only difficult to locate the families for follow up, but also to encourage them to participate.

\section{Limitations and Strengths}

We have identified two limitations in our study: (a) We did not have information corresponding to all variables used in this study about those who participated and those lost to follow up, which could generate a potential for attrition bias in the sample composition; (b) Reports on the mental health assessment (SDQ) were completed only by parents. The literature indicates that prediction of diagnostic status is optimal when parent, teacher and selfreports are available, which was not possible in this study.

The primary strength of this study is that it provides preliminary information about the mental health problems of SGA and AGA children at 10 years. This is especially important for a developing country like Brazil, in which studies of this nature are still few. A second contribution is the identification of environmental factors associated with risk conditions for mental health problems. We believe this is the first step in investigating the culture and context of psychopathology in children, helping to determine the ways in which it is manifested.

\section{References}

Alexander, G. R., Himes, J. H., Kaufman, R. B., Mor, J., \& Kogan, M. (1996). A United States National reference for fetal growth. Obstetrics and Gynecology, 87, 163-168. doi:10.1016/0029-7844(95)00386-X

Anselmi, L., Menezes, A. M. B., Barros, F. C., Hallal, P. C., Araújo, C. L., Domingues, M. R., \& Rohde, L. A. (2010). Determinantes precoces de problemas de atenção e hiperatividade na adolescência: A visita de 11 anos da coorte de nascimentos de Pelotas, Rio Grande do Sul, Brasil, 1993. Cadernos de Saúde Pública, 26(10), 1954-1962. doi:10.1590/ S0102-311X2010001000012

Associação Brasileira de Empresas de Pesquisa. (2008). Questionário de classificação sócio-econômico. Recuperado em 6 de dezembro, 2011, de http://www.abep.org/novo/Content. aspx?ContentID $=302$

Bhutta, A. T., Cleves, M. A., Casey, P. H., Cradock, M. M., \& Anand, K. J. (2002). Cognitive and behavioral outcomes of school-aged children who were born preterm: A metaanalysis. Jama, 288(6), 728-737. doi:10.1001/jama.288.6.728

Canino, G., \& Alegría, M. (2008). Psychiatric diagnosis - Is it universal or relative to culture? Journal of Child Psychology and Psychiatry, 49(3), 237-250. doi:10.1111/j.14697610.2007.01854.x

Cardoso, V. C., Simões, V. M. F., Barbieri, M. A., Silva, A. A. M., Bettiol, H., Alves, M. T. S. S. B., \& Goldani, M. Z. (2007). Profile of three Brazilian birth cohort studies in Ribeirão Preto, SP and São Luís, MA. Brazilian Journal of Medical and Biological Research, 40, 1165-1176. doi:10.1590/S0100879X2006005000148

Casey, P. H., Whiteside-Mansell, L., Barret, K., Bradley, R. H., \& Gargus, R. (2006). Impact of prenatal and/or postnatal growth problems in low birth weight preterm infants on school-age outcomes: An 8-year longitudinal evaluation. Pediatrics, 118, 1078-1086. doi:10.1542/peds.2006-0361

Cury, C. R., \& Golfeto, J. H. (2003). Questionário de capacidades e dificuldades (SDQ): Um estudo em escolares de Ribeirão Preto. Revista Brasileira de Psiquiatria, 25, 139-145. doi:10.1590/S1516-44462003000300005

Emond, A. M., Lira, P. I. C., Lima, M. C., Grantham-McGregor, S., \& Ashworth, A. (2006). Development and behaviour of low-birthweight term infants at 8 years in Northeast Brazil: A longitudinal study. Acta Pcediatrica, 95, 1249-1257. doi:10.1080/08035250600615127

Ferrioli, S. H. T., Marturano, E. M., \& Puntel, L. P. (2007). Contexto familiar e problemas de saúde mental infantil no Programa de Saúde da Família. Revista de Saúde Pública, 41(2), 251-259. doi:10.1590/S0034-89102006005000017

Gallo, E. A. G., Anselmi, L., Dumith, S. C., Scazufca, M., Menezes, A. M. B., Hallal, P. C., \& Matijasevich, A. (2011). Tamanho ao nascer e problemas de saúde mental aos 11 anos em uma coorte brasileira de nascimentos. Cadernos de Saúde Pública, 27(8), 1622-1632. doi:10.1590/S0102311X2011000800017

Gardosi, J. (2006). New definition of small for gestational age based on fetal growth potential. Hormone Research in Pediatrics, 65(Suppl. 3), 15-18. doi:10.1159/000091501

Goldenberg, R. L., Hoffman, H. J., \& Cliver, S. P. (1998). Neurodevelopmental outcome of small-for-gestational-age infants European Journal of Clinical Nutrition, 52(Suppl. 1), 54-58. 
Goodman, R. (1997). The strengths and difficulties questionnaire: A research note. Journal of Child Psychology and Psychiatry; 38, 581-586. doi:10.1111/j.1469-7610.1997.tb01545.x

Guellec, I., Lapillonne, A., Renolleau, S., Charlaluk, M.-L., Roze, J.-C., Marret, S., ...EPIPAGE Study Group. (2011). Neurologic outcomes at school age in very preterm infants born with severe or mild growth restriction. Pediatrics, 127 , e883-e891. doi:10.1542/peds.2010-2442

Hackett, R., \& Hackett, L. (1999). Child psychiatry across cultures. International Review of Psychiatry, 11, 225-235. doi:10.1111/j.1469-7610.2007.01854.x

Hayes, B., \& Sharif, F. (2009). Behavioural and emotional outcome of very low birth weight infants - Literature review. Journal of Maternal-Fetal and Neonatal Medicine, 22, 849856. doi:10.1080/14767050902994507

Hollo, O., Rautava, P., Korhonen, T., Helenius, H., Kero, P., \& Sillanpãã, M. (2002). Academic achievement of small-forgestational-age children at age 10 years. Archives of Pediatrics and Adolescent Medicine, 156, 179-187. doi:10.1001/ archpedi.156.2.179

Indredavik, M. S., Vik, T., Heyerdahl, S., Kulseng, S., \& Brubakk, A. M. (2005). Psychiatric symptoms in low birth weight adolescents, assessed by screening questionnaires. European Child and Adolescent Psychiatry, 14(4), 226-236. doi:10.1136/adc.2003.038943

Kieling, C., Baker-Henningham, H., Belfer, M., Conti, G., Ertem, I., Omigbodun, O., ...Rahman, A. (2011). Child and adolescent mental health worldwide: Evidence for action. Lancet, 378, 1515-1525. doi:10.1016/S0140-6736(11)60827-1

Linhares, M. B. M., Chimello, J. T., Bordin, M. B. M., Carvalho, A. E. V., \& Martinez, F. E. (2005). Desenvolvimento psicológico na fase escolar de crianças nascidas pré-termo em comparação com crianças nascidas a termo. Psicologia: Reflexão e Crítica, 18(1), 109-117. doi:10.1590/S141373722005000200010

Lundgren, E. M., \& Tuvemo, T. (2008). Effects of being born small for gestational age on long-term intellectual performance. Best Practice \& Research Clinical Endocrinology \& Metabolism, 22, 477-488. doi:10.1016/j. beem.2008.01.014

Masten, A. S., \& Gerwitz, A. H. (2006). Vulnerability and resilience in early child development. In K. McCartney \& D. Phillips (Eds.), Blackwell handbook of early childhood development (pp. 22-43). Chichester, UK: Blackwell. doi:10.1111/b.9781405120739.2005.00004.x

O'Keeffe, M. J., O'Callaghan, M., Williams, G. M., Najman, J. M., \& Bor, W. (2003). Learning, cognitive, and attentional problems in adolescents born small for gestational age. Pediatrics, 112(2), 301-307. doi:10.1542/peds.112.2.301

Pallotto, E. K., \& Kilbride, H. W. (2006). Perinatal outcome and later implications of intrauterine growth restriction. Clinical Obstetrics and Gynecology, 49, 257-269.

Pryor, J., Silva, P. A., \& Brooke, M. (1995). Growth, development and behaviour in adolescents born small-for-gestationalage. Journal of Paediatrics and Child Health, 31, 403-407. doi:10.1111/j.1440-1754.1995.tb00847.x

Rodriguez, J. D. M., Silva, A. A. M., Bettiol, H., Barbieri, M. A., \& Rona, R. (2011). The impact of perinatal and socioeconomic factors on mental health problems of children from a poor Brazilian city: A longitudinal study. Social Psychiatry and Psychiatric Epidemiology, 46, 381-391. doi:10.1007/ s00127-010-0202-6
Rohde, L. A. (2011). The need of epidemiological data on child mental disorders from low-middle income countries. European and Child Adolescent Psychiatry, 20, 497-498. doi:10.1007/s00787-011-0217-x

Sameroff, A. J., \& Fiese, B. H. (2005). Models of development and developmental risk. In C. H. Zeanah Jr. (Ed.), Handbook of infant mental health ( $2^{\text {nd }}$ ed., pp. 3-19). New York: The Guilford Press. doi:10.2989/17280580709486638

Silva, A. A., Barbieri, M. A., Cardoso, V. C., Batista, R. F., Simões, V. M., Vianna, E. O., ...Bettiol, H. (2011). Prevalence of non-communicable diseases in Brazilian children: Follow-up at school age of two Brazilian birth cohorts of the 1990's. BMC Public Health, 11, 486-518. doi:10.1186/14712458-11-486

Sommerfelt, K., Andersson, H. W., Sonnander, K., Ahlsten, G., Ellertsen, B., Markestad, T., ...Bakketeig, L. S. (2001) Behavior in term, small for gestational age preschoolers. Early Human Development, 65(2), 107-121. doi:10.1016/ S0378-3782(01)00200-6

Thompson, L., Kemp, J., Wilson, P., Pritchett, R., Minnis, H., Toms-Whittle, L., ...Gillberg, C. (2010). What have birth cohort studies asked about genetic, pre- and perinatal exposures and child and adolescent onset mental health outcomes? A systematic review. European Child \& Adolescent Psychiatry, 19, 1-15. doi:10.1007/s00787-009-0045-4

Walker, S. P., Wachs, T. D., Gardner, J. M., Lozoff, B., Wasserman, G. A., Pollitt, E., ...International Child Development Steering Group. (2007). Child development: Risk factors for adverse outcomes in developing countries. Lancet, 369, 145 157. doi:10.1016/S0140-6736(07)60076-2

Wiles, N. J., Peters, T. J., Heron, J., Gunnell, D., Emond, A., \& Lewis, G. (2006). Fetal growth and childhood behavioral problems: Results from the ALSPAC cohort. American Journal of Epidemiology, 163, 829-837. doi:10.1093/aje/kwj108

Winchester, S. B., Sullivan, M. C., Marks, A. K., Doyle, T., DePalma, J., \& McGrath, M. M. (2009). Academic, social, and behavioral outcomes at age 12 of infants born preterm. Western Journal of Nursing Research, 31, 853-871. doi:10.1177/0193945909339321

Zahn-Waxler, C., Klimes-Dougan, B., \& Slattery, M. J. (2000). Internalizing problems of childhood and adolescence: Prospects, pitfalls, and progress in understanding the development of anxiety and depression. Development and Psychopathology, 12, 443-466. doi:10.1017/S0954579400003102

Zubrick, S. R., Kurinczuk, J. J., McDermott, B. M. C., McKelvey, R. S., Silburn, S. R., \& Davies, L. (2000). Fetal growth and subsequent mental health problems in children aged 4 to 13 years. Developmental Medicine and Child Neurology, 42(1), 14-20. doi:10.1111/j.1469-8749.2000.tb00019.x 